OPEN ACCESS

Edited by:

Luis Cláudio Nascimento da Silva, Universidade Ceuma, Brazil

Reviewed by: Cesar de la Fuente-Nunez, University of Pennsylvania, United States

Maria Bagattini,

University of Naples Federico II, Italy Lucas Pinheiro Dias,

Federal University of Ceará, Brazil

*Correspondence:

Jian Peng

jianpeng@gmc.edu.cn

Jianwei Wu

wjw@gmc.edu.cn

tThese authors have contributed equally to this work

Specialty section:

This article was submitted to Antimicrobials, Resistance

and Chemotherapy,

a section of the journal

Frontiers in Microbiology

Received: 16 February 2020 Accepted: 12 June 2020

Published: 11 August 2020

Citation:

Liu W, Wu Z, Mao C, Guo G, Zeng Z, Fei Y, Wan S, Peng J and Wu J (2020) Antimicrobial Peptide

Cec4 Eradicates the Bacteria of Clinical Carbapenem-Resistant Acinetobacter baumannii Biofilm

Front. Microbiol. 11:1532.

doi: 10.3389/fmicb.2020.01532

\section{Antimicrobial Peptide Cec4 Eradicates the Bacteria of Clinical Carbapenem-Resistant Acinetobacter baumannii Biofilm}

\author{
Weiwei Liu' ${ }^{1,2,3 t}$, Zhaoying Wu $\mathrm{W}^{1,2,3 t}$, Chengju Mao ${ }^{2,3}$, Guo Guo ${ }^{3}$, Zhu Zeng ${ }^{1,3}$, Ying Fei ${ }^{4}$, \\ Shan Wan ${ }^{4}$, Jian Peng ${ }^{1,2,3 *}$ and Jianwei $W^{3 *}$ \\ ${ }^{1}$ Immune Cells and Antibody Engineering Research Center of Guizhou Province, Guizhou Medical University, Guiyang, \\ China, ${ }^{2}$ Key Laboratory of Environmental Pollution Monitoring and Disease Control, Ministry of Education, Guizhou Medical \\ University, Guiyang, China, ${ }^{3}$ The Key and Characteristic Laboratory of Modern Pathogen Biology, Basic Medical College, \\ Guizhou Medical University, Guiyang, China, ${ }^{4}$ The Center for Clinical Laboratories, The Affiliated Hospital of Guizhou Medical \\ University, Guiyang, China
}

The drug resistance rate of Acinetobacter baumannii increases year on year, and the drugs available for the treatment of carbapenem-resistant $A$. baumannii (CRAB) infection are extremely limited. $A$. baumannii, which forms biofilms, protects itself by secreting substrates such as exopolysaccharides, allowing it to survive under adverse conditions and increasing drug resistance. Antimicrobial peptides are small molecular peptides with broad-spectrum antibacterial activity and immunomodulatory function. Previous studies have shown that the antimicrobial peptide Cec4 has a strong effect on A. baumannii, but the antibacterial and biofilm inhibition of this antimicrobial peptide on clinical carbapenem resistance $A$. baumannii is not thoroughly understood. In this study, it was indicated that most of the 200 strains of CRAB were susceptible to Cec4 with a MIC of $4 \mu \mathrm{g} / \mathrm{ml}$. Cec4 has a strong inhibitory and eradication effect on the CRAB biofilm; the minimum biofilm inhibition concentration (MBIC) was 64-128 $\mu \mathrm{g} / \mathrm{ml}$, and the minimum biofilm eradication concentration (MBEC) was 256$512 \mu \mathrm{g} / \mathrm{ml}$. It was observed that Cec4 disrupted the structure of the biofilm using scanning electron microscopy (SEM) and confocal laser scanning microscopy (CLSM). A comparative transcriptome analysis of the effects of the antimicrobial peptide Cec4 on CRAB biofilm, identified 185 differentially expressed genes, including membrane proteins, bacterial resistance genes, and pilus-related genes. The results show that multiple metabolic pathways, two-component regulation systems, quorum sensing, and antibiotic synthesis-related pathways in A. baumannii biofilms were affected after Cec4 treatment. In conclusion, Cec4 may represent a new choice for the prevention and treatment of clinical infections, and may also provide a theoretical basis for the development of antimicrobial peptide drugs.

Keywords: antimicrobial peptide, Cec4, CRAB, biofilm, transcriptome 


\section{INTRODUCTION}

Acinetobacter baumannii is a non-fermenting Gram-negative bacterium, and infections often occur in patients with poor immunity, especially in patients in intensive care units or in patients undergoing invasive surgery (Handal et al., 2017). It can cause hospital-acquired pneumonia, especially ventilatorassociated pneumonia, bacteremia, urinary tract infection, secondary meningitis, etc., with a high mortality rate (Bentancor et al., 2012). At the same time, A. baumannii is prone to drug resistance and is even resistant to carbapenem antibiotics, including imipenem and meropenem (Maragakis and Perl, 2008). At present, most antibiotics, except tigecycline and polymyxin, do not affect it (Dafopoulou et al., 2019). Although tigecycline has a broad antibacterial spectrum and good antibacterial activity, the blood concentration is low, only $0.7-0.8 \mathrm{mg} / \mathrm{L}$ (Cai and Wang, 2011). Therefore, it remains controversial to use tigecycline to treat blood-related infections (Akalay et al., 2020); moreover, polymyxin has greater renal and neurotoxicity, limiting its use (Spapen et al., 2011). By organism, the highest overall rates of multidrug resistance reported in a study were among A. baumannii isolates, for which $44 \%$ of isolates collected globally were multidrug-resistant bacteria. Additionally, the treatment options for infections caused by such organisms are limited, which deserves attention (Giammanco et al., 2017). Recently, the World Health Organization (WHO) classified carbapenemresistant A. baumannii (CRAB) as the first in the list of key pathogens for the development of new antibiotics (O'Shea, 2012).

When A. baumannii forms biofilms, its resistance increases rapidly (Eze et al., 2018). Biofilms are composed of bacteria that irreversibly adhere to the surface of living or nonliving organisms and are surrounded by a secreted matrix of extracellular polysaccharide, protein, and DNA. Once the special structure forms, the bacteria express completely different genes from planktonic bacteria, with significant differences in morphology, physical and chemical properties, and antibiotic susceptibility (Jamal et al., 2018). The ability to form biofilms on abiotic surfaces under adverse conditions makes the biofilm phenotype an important virulence factor for A. baumannii infection (Eze et al., 2018). At the same time, it is beneficial for bacteria to survive on nutritionally limited abiotic surfaces and stressful environmental conditions (Alvarez-Fraga et al., 2016). Bacterial biofilms cause at least $65 \%$ of human infections, particularly implantable device-related infections and chronic disease infections (Williams and Costerton, 2012). Therefore, there is an urgent need for drugs that effectively treat biofilmassociated infections. At present, it has been reported that some natural product extracts and compounds can treat bacterial biofilms. Water extract of Galla chinensis suppressed biofilm and extracellular matrix formation of Staphylococcus aureus (Wu et al., 2019). Qin et al. (2014) reported the effects of two natural compounds on methicillin-resistant Staphylococcus aureus (MRSA). Ursolic acid can inhibit the formation of biofilms, while resveratrol combined with vancomycin can inhibit pre-formed mature biofilms. Silver nanoparticles do not affect the growth of planktonic Staphylococcus aureus but can reduce the production of biofilms at a concentration of $50 \mu \mathrm{g} / \mathrm{ml}$
(Singh et al., 2019). However, in many cases, these anti-biofilm active ingredients are not sufficient enough to completely inhibit or eliminate bacterial biofilms and lack broad-spectrum antibiofilm efficacy.

Antimicrobial peptides (AMPs) have a broad antibacterial spectrum and a wide range of sources, and have unique antibacterial mechanisms, making them less prone to drug resistance. It is generally believed that AMPs exert their microbicidal activity mainly through targeting the cell membrane by penetration and cell lysis activities (Aisenbrey et al., 2019). The MIC of human-derived cationic peptide LL-37 and its truncated fragments against drug-resistant A. baumannii is 16$32 \mu \mathrm{g} / \mathrm{ml}$, and it inhibits the formation of biofilms (Feng et al., 2013). The peptide IDR-1018 exhibits broad-spectrum anti-biofilm activity against a variety of hospital pathogens, including Pseudomonas aeruginosa and Klebsiella pneumonia (de la Fuente-Nunez et al., 2014). Therefore, antimicrobial peptides are expected to become new drugs for the treatment of bacterial biofilm and associated infections (Kim et al., 2020; Neshani et al., 2020). Our previous study found that the peptide Cec4 had a minimum inhibitory concentration (MIC) of $4 \mu \mathrm{g} / \mathrm{ml}$ against an A. baumannii reference strain (ATCC19606), which is superior to the reported similar cecropin antimicrobial peptides $\mathrm{Cec} 1$, cecropin A and fusion peptide CA. (1-8) M (1-18) (Saugar et al., 2002; Batoni et al., 2011; Long et al., 2017). It was confirmed in the previous report that the semi-inhibitory concentration of Cec4 on the formation of standard A. baumannii biofilms (to inhibit the formation of biofilm by $50 \%$ ) is about $4 \mu \mathrm{g} / \mathrm{ml}$; this peptide is non-hemolytic on human red blood cells at high concentrations $(100 \times$ MIC) (Peng et al., 2019). However, whether the antimicrobial peptide Cec4 can inhibit CRAB and its biofilm to the same extent as with the A. baumannii (ATCC19606), remains elusive. Therefore, 200 strains of clinical CRAB were collected, and their ability to form biofilms was tested. Furthermore, the susceptibility and biofilm formation of A. baumannii isolates to the antimicrobial peptide Cec4 were evaluated, and the molecular mechanism of Cec4 on bacterial biofilm was analyzed by transcriptome analysis. In conclusion, this study is expected to provide new ideas for the treatment of clinical infections and presents a theoretical basis for research and development into new antibiotics.

\section{MATERIALS AND METHODS}

\section{Synthesis and Preparation of Peptides}

Antimicrobial peptide Cec4 (GWLKKIGKKIERVGQNTRD ATIQAIGVAQQAANVAATLKGK) was synthesized by Gil Biochemical Co., Ltd., Shanghai. Using solid-phase chemical synthesis, the purity (HPLC) $>97 \%$ and the mass of the peptide determined by spectrometry. It was dissolved to $10 \mathrm{mg} / \mathrm{ml}$ with distilled deionized $\mathrm{H}_{2} \mathrm{O}\left(\mathrm{ddH}_{2} \mathrm{O}\right)$ and stored at $-80^{\circ} \mathrm{C}$ for further analysis.

\section{Bacterial Isolates and Growth Conditions}

From October 2017 to December 2018, 200 isolates of CRAB from clinical samples of patients from the affiliated hospital 
of Guizhou Medical University were collected and duplicate samples from the same patient were excluded. All of them come from sputum, blood, urine and so on. The collection and use of clinically isolated strains were approved by the Institutional review board (IRB) of Guizhou Medical University, China. The studies involving human participants were reviewed and approved by Guizhou Medical University and the affiliation of the ethics committee. The patients provided written informed consent to participate in this study. Minimum inhibitory concentrations (MICs) of these strains to nine antibiotics including amikacin, ertapenem, imipenem, meropenem, ceftazidime, ciprofloxacin, ceftriaxone, levofloxacin, and cefepime were assessed on MicroScan WalkAway 40-SI Analyzer (SIEMENS, Germany), according to the manufacturer's instructions. Resistance to cefotaxime was assessed using the standard disc diffusion method (Oxoid, Hampshire, United Kingdom). Interpretive breakpoints for susceptible, intermediate, and resistant were consistent with Clinical and Laboratory Standards Institute guidelines (Humphries et al., 2018). In order to ensure the accuracy of bacterial identification, the $16 \operatorname{SrRNA}$ and $r p o B$ genes of all strains were amplified, and PCR products were sequenced and analyzed. A. baumannii (ATCC19606) is a biofilm-forming positive strain. Escherichia coli ATCC25922 and Pseudomonas aeruginosa ATCC27853 were used as quality control bacteria. The above strains are stored in the Pathogen Biology Laboratory of Guizhou Medical University. Strains were grown on Mueller-Hinton Broth (MHB), Typic Soy Broth (TSB) or Luria-Bertani (LB) agar plates and incubated at $37^{\circ} \mathrm{C}$.

\section{Detecting the Minimum Inhibitory Concentration (MIC) Value}

According to a previous study (Wiegand et al., 2008), the MIC of Cec4 peptide against 200 strains of CRAB was assessed using the broth microdilution assay in MHB. After adding different concentrations of antimicrobial peptide Cec4, the 96-well plate was placed in a constant temperature incubator at $37^{\circ} \mathrm{C}$. After incubation for $24 \mathrm{~h}$, it was observed. The MIC was defined as the lowest drug concentration that can inhibit bacterial growth by visual evaluation.

\section{Quantitative Biofilm Formation Assay}

According to the crystal violet staining method of a previous study (O'Toole, 2011), the 96-well tissue culture plate method was utilized for a quantitative evaluation of biofilm formation by 200 strains of CRAB. A. baumannii ATCC19606 was used as the positive control, and TSB medium without bacteria was used as the negative control. Absorbance at $570 \mathrm{~nm}$ (OD570) was measured for each well to obtain quantitative data on biofilm formation as described previously (Badmasti et al., 2015). The mean \pm standard deviation of the OD value of the negative control was defined as ODc. Based on the OD value, the strains were divided into the following four groups: the OD value of the test strain was compared with ODc, and $\mathrm{OD}_{570} \leq \mathrm{ODc}$ was negative for biofilm formation $(-)$; $\mathrm{ODc}<\mathrm{OD}_{570} \leq 2 \times \mathrm{ODc}$ indicates weak biofilm formation
$(+) ; 2 \times$ ODc $<$ OD570 $\leq 4 \times$ ODc indicates moderate biofilm formation $(++) ; 4 \times$ ODc $<$ OD570 indicates strong biofilm formation $(+++)$.

\section{Detection of the Minimum Biofilm Inhibition Concentration (MBIC) and Minimum Biofilm Eradication Concentration (MBEC)}

In order to detect the inhibitory effect of Cec4 peptide on the growth of biofilms, a method described in the literature was used with modifications (Abouelhassan et al., 2017). Briefly, $200 \mu \mathrm{l}$ of bacterial cells $\left(1 \times 10^{6} \mathrm{CFU} / \mathrm{ml}\right)$ of 10 strains (CRAB 3, 4, $53,55,78,117,120,128,130,136)$ with the strongest biofilm formation ability was inoculated in a polyethylene 96-well plate; TSB culture medium containing no bacteria was used as the blank control, and the plate was incubated at $37^{\circ} \mathrm{C}$ for $24 \mathrm{~h}$. The culture medium was subsequently removed, and wells were carefully washed with PBS three times to remove planktonic bacteria. And then, $200 \mu \mathrm{l}$ of TSB culture medium containing Cec4 in serial doubling dilutions was added to each well. TSB medium without an antimicrobial peptide was used as a negative control, and plates were incubated at $37^{\circ} \mathrm{C}$ for $24 \mathrm{~h}$. If OD600 $<0.1$, there was no bacterial growth, and the lowest concentration without bacterial growth at this time point was recorded; this is the MBIC. Then, cells and peptide in the 96-well cell culture plate were washed with PBS, and $200 \mu \mathrm{l}$ of TSB culture medium was added to each well. The plate was incubated at $37^{\circ} \mathrm{C}$ for $24 \mathrm{~h}$ to regrow the surviving biofilm bacteria. An OD600 $<0.1$ indicated that there was no bacterial growth. The lowest concentration at which no bacterial growth was recorded is the MBEC. In order to evaluate the eradication efficiency of Cec4 on the biofilm, the culture in the wells was removed and washed with PBS to remove non-adherent cells. The biofilm was quantified by the aforementioned method, and calculated using the equation $\left(1-\frac{\text { OD570 of the test }}{\text { OD570 of non }- \text { treated control }}\right) \times 100$.

\section{Scanning Electron Microscopy (SEM)}

According to a previous report (Ramalingam and Lee, 2018), the biofilm of CRAB 55 was cultured in vitro in a 6-well plate, and a sterile polylysine-treated cover glass and a sterile medical catheter cut at a length of $1 \mathrm{~cm}$ were added in advance as a biofilm growth carrier. Samples were processed by gradient dehydration with 20 , $50,70,90$, and $100 \%$ ethanol/tert-butanol mixture. The samples were dried in a critical point dryer and placed in a high vacuum evaporator, then sprayed gold with an ion sprayer and observed using a scanning electron microscope (Hitachi S-3400).

\section{Confocal Laser Scanning Microscope Analysis}

Confocal laser scanning microscopy analysis was carried out according to a previous study (Bortolin et al., 2016). A sterile polylysine-treated cover glass was used as the carrier, and the biofilm of CRAB 55 was cultivated according to the method of the previous step. Then, $1 \mathrm{mM}$ SYTO9 and $10 \mathrm{mM}$ propidium iodide (PI) were added and incubated for $15 \mathrm{~min}$ in the dark. 
An Olympus Fluoview FV1000 confocal microscope (Olympus, Markham, ON, Canada) was used to obtain a fluorescence image. The bottom of the biofilm to the surface was scanned layer by layer along the $Z$-axis to record the earliest and last disappearance of fluorescence, and the corresponding biofilm thickness was calculated accordingly; each layer was $1 \mu \mathrm{m}$. The resulting stacks of images were quantified using an image processing package (Image), United States) and subsequently rendered into threedimensional mode using image analysis software (Imaris 7.2.3, Bitplane, Switzerland).

\section{Motility Assays}

As described by a previous study (McQueary and Actis, 2011), twitching plates were made with $10 \mathrm{~g} / \mathrm{l}$ tryptone, $5 \mathrm{~g} / \mathrm{l}$ yeast extract and $5 \mathrm{~g} / \mathrm{l} \mathrm{NaCl}$ and $1 \%$ Eiken agar, with different concentrations of Cec4 (or none). A single colony of CRAB 55 was picked from a normal LB agar $(1.5 \%$, wt/vol) plate and inoculated vertically to the bottom of the plate, so that it could grow at the intersection of the bottom of the agar layer and the culture dish. The plate was incubated at $37^{\circ} \mathrm{C}$ for $24 \mathrm{~h}$, and motility was evaluated by observing the formation of a transparent halo around the growing colonies and measuring the diameter. Twitching motility assays were conducted on at least three separate occasions. As described in a previous study (Harding et al., 2013), surface motility plates are comprised of $5 \mathrm{~g} / \mathrm{l}$ tryptone, $2.5 \mathrm{~g} / \mathrm{l} \mathrm{NaCl}$ and $0.35 \%$ Eiken agar, with different concentrations of Cec4 or not. The bacteria were cultured to the logarithmic phase, then a $2 \mu \mathrm{l}$ of aliquot of an overnight culture was stabbed into the surface of the center of the plate, and motility was measured after incubating the plate at $37^{\circ} \mathrm{C}$ for $24 \mathrm{~h}$. Surfaceassociated motility assays were conducted on at least three separate occasions.

\section{Quantitative RT-PCR}

According to a previous study (He et al., 2015), biofilm formation of CRAB 55 was conducted as described above, and after the biofilm had been treated with Cec4 or not, it was scraped from the plate with a cell spatula. Total RNA was extracted using Trizol. RNA was quantified and quality was assessed using a NanoDrop spectrophotometer (ND-2000, Thermo Scientific, Loughborough, United Kingdom), and the final RNA concentration was adjusted to $1 \mathrm{ng} / \mu \mathrm{l}$. cDNA was synthesized in a $20 \mu \mathrm{l}$ reaction mixture using a PrimeScript RT reagent Kit with gDNA Eraser. According to the SYBR Premix Ex Taq TM Kit (Takara, Dalian, China) protocol, the reactions were run on an ABI7300 real-time PCR system using a $20 \mu \mathrm{l}$ reaction volume. Gene expression levels were normalized to the abundance of A. baumannii $16 S$ rRNA. Target genes included CsuE, BfmR, BfmS, AbaI, and Bap. The primers were designed with reference to the GenBank sequences. The primer sequences are shown in the Supplementary Table S1.

\section{RNA-Seq}

RNA Isolation, Library Construction and Sequencing

The four strains CRAB 4, 55, 78, and 117 with the strong biofilmforming ability and similar characteristics were selected as four biological replicates. The logarithmic growth culture was washed twice in sterile PBS and diluted to $10^{6}$ cells $/ \mathrm{ml}$ in TSB. Then, $4 \mathrm{ml}$ of the culture was added to a flat-bottomed 6-well plate (Corning, United States) and incubated at $37^{\circ} \mathrm{C}$ for $24 \mathrm{~h}$ to form a biofilm. Samples were collected as a control group (Control 1, Control 2, Control 3 and Control 4). For the Cec4 treatment group (ABF1, $\mathrm{ABF} 2, \mathrm{ABF} 3$, and $\mathrm{ABF} 4)$, after forming mature biofilms, non-adherent cells were removed, and TSB culture solution containing $4 \times \mathrm{MIC}(16 \mu \mathrm{g} / \mathrm{ml})$ of Cec 4 was added. Biofilm samples were collected $24 \mathrm{~h}$ later.

The total RNA of these samples was extracted using Trizol reagent (Sigma-Aldrich, United States) according to the previously described method. The quality and quantity were determined by a NanoPhotometer spectrophotometer (IMPLEN, CA, United States) and an Agilent 2100 bioanalyzer (Agilent Technologies, CA, United States). RNA-seq library construction and RNA sequencing were performed by the Novogene Corporation (Beijing, China). Sequence reads were deposited at the National Center for Biotechnology Information under BioProject PRJNA607078 as SAMN14120700, SAMN14120701, SAMN14120702, SAMN14 120703, SAMN14120704, SAMN14120705, SAMN14120706, SAMN14120707 ${ }^{1}$.

\section{Identification of Differentially Expressed Genes and Annotation}

Raw reads were generated from the image data and stored as FASTQ format. Raw data were filtered to remove adaptor contaminated and low-quality sequences and to obtain clean reads. Genomic mapping of the filtered sequence was performed using Bowtie2-2.2.3 (Langmead and Salzberg, 2012). The reference genome and gene model annotation file of A. baumannii AB030 was downloaded from GenBank (NZ_CP009257.1). HTSeq v0.6.1 was used to count the read numbers mapped to each gene. The expected number of fragments per kilobase of transcript sequence per million base pairs sequenced (FPKM) of each gene was calculated based on the length of the gene and reads count mapped to this gene (Trapnell et al., 2012). Differential expression analysis of two groups (four biological replicates per group) was performed using the DEGSeq R package (??) (Anders and Huber, 2012). The resulting $p$-values were adjusted using the Benjamini and Hochberg approach for controlling the false discovery rate. Genes with a corrected $p$-value $<0.05$ and $\log _{2}$ (Fold change) $>1$ found by DEGSeq were assigned as differentially expressed. Gene ontology (GO) enrichment analysis of differentially expressed genes was implemented by the GOseq $\mathrm{R}$ package. The GO enrichment analysis of differentially expressed genes was achieved by GOseq software, and KOBAS software was used to test the statistical enrichment of differentially expressed genes in KEGG pathways (Kanehisa et al., 2008; Young et al., 2010). Significantly enriched KEGG pathways and GO terms were identified by a $p$-value $<0.05$ using Fisher's exact test and a $p$-value $<0.01$ in the hypergeometric distribution, respectively, and adjusted by false discovery rates (FDR) (Rivals et al., 2007; Boca and Leek, 2018).

\footnotetext{
${ }^{1}$ https://www.ncbi.nlm.nih.gov/sra/PRJNA607078
} 


\section{Statistical Analysis}

Statistical analysis was performed using GraphPad Prism software version 6.0 (Graph Pad Software, San Diego, CA, United States) and Student's $t$-test. Data are expressed as mean \pm standard deviation (SD). All experiments were performed in triplicate. A $p$-value $<0.05$ was considered statistically significant.

\section{RESULTS}

\section{Cec4 Inhibits Clinical Resistant Bacteria}

It was reported that large differences have been shown between $A$. baumannii strains. In previous studies, Cec4 showed outstanding antibacterial activity against $A$. baumannii. Its MIC against standard A. baumannii(ATCC19606)was $4 \mu \mathrm{g} / \mathrm{ml}$. In order to study its antibacterial effect on clinical CRAB, the susceptibility of CRAB to Cec4 was tested. As shown in Figure 1A, $98.5 \%$ of the 200 isolates of CRAB were susceptive to the peptide Cec4 with a MIC $\leq 4 \mu \mathrm{g} / \mathrm{ml}$. Only $1.5 \%$ of the strains had MIC $>4 \mu \mathrm{g} / \mathrm{ml}$, which were 8 and $16 \mu \mathrm{g} / \mathrm{ml}$, respectively (Supplementary Table S2). Therefore, the peptide Cec4 has great antibacterial effects on the majority of clinical carbapenem resistant bacteria.

\section{The Biofilm Formation Ability of CRAB Strains}

Bacteria in the form of biofilms have increased resistance to antibacterial drugs, external environmental pressures, and the host's immune system, which has brought great challenges to clinical treatment. Based on crystal violet staining, the ability of 200 isolates of CRAB to form biofilms was studied. As shown in Figure 1B, the OD570 value of the positive control strain ATCC19606 in the experimental plate was $1.191 \pm 0.012$, and the negative control was $0.111 \pm 0.005$. The OD570 value of the 200 resistant bacteria was between 0.1 and 1.9 (Supplementary Table S2). All 200 strains of CRAB were able to form biofilms. Among them, 53 strains (26.5\%) had strong biofilm formation ability, 120 strains $(60 \%)$ were moderate and 27 strains $(13.5 \%)$ were weak.

\section{Cec4 Inhibits and Eradicates Biofilm of CRAB Strains}

After bacteria formed the biofilm, their resistance to drugs was greatly enhanced. Our previous studies have demonstrated that antimicrobial peptide Cec4 at $0.5 \mu \mathrm{g} / \mathrm{mL}$ can inhibit the formation of A. baumannii biofilm (Peng et al., 2019). Regarding biofilm formation ability, the 10 strongest strains were selected to evaluate the ability of Cec4 to inhibit and eradicate their biofilm. As shown in Supplementary Table S2, the antimicrobial peptide Cec4 can inhibit the biofilm of the strains with the strongest CRAB biofilm formation ability at $64-128 \mu \mathrm{g} / \mathrm{ml}$, and can eradicate the biofilm at $256-512 \mu \mathrm{g} / \mathrm{ml}$. In order to determine the effect of $\mathrm{Cec} 4$ on the removal of biofilms, after the formation of mature biofilms, different concentrations of Cec 4 were added to the culture for $24 \mathrm{~h}$. The crystal violet staining method was used to measure the absorbance at $570 \mathrm{~nm}$ to calculate the clearance rate of different concentrations of the peptide on mature biofilms. The results showed that $1 \times \operatorname{MIC}(4 \mu \mathrm{g} / \mathrm{ml})$ could clear more than $20 \%$ of mature biofilms, with MBEC $_{50}$ of $16 \mu \mathrm{g} / \mathrm{ml}$ and $\mathrm{MBEC}_{80}$ of $128 \mu \mathrm{g} / \mathrm{ml}$ (Figure 1C).

\section{Cec4 Destroys the Structure of Biofilms}

Acinetobacter baumannii colonizes the surface of medical equipment and indwelling medical devices (including urinary catheters) to form biofilms, leading to long-term and recurrent infections in patients (Lin et al., 2019). Coverslips and urinary catheters were used as carriers to evaluate the ability of Cec4 to remove the biofilms formed on them. Clinical CRAB forms biofilm on coverslips and catheters, and the effects of Cec4 on the biofilm are shown in Figure 2. After $24 \mathrm{~h}$ in culture, for the untreated group, the A. baumannii that adhered to the coverslip mostly was bacilliform; the biofilm was dense and the cell membrane was intact, forming a typical "mushroom cloud" three-dimensional structure. After treatment with Cec4 at a concentration of $1 \times \mathrm{MIC}(4 \mu \mathrm{g} / \mathrm{ml})$, the biofilm structure was destroyed, and the cells were loosely distributed, and some cell surfaces appeared to be attacked. A. baumannii adhered to the catheter was mostly spherical and formed a thick biofilm, covered with extracellular substrates. After treatment with Cec4 ( $4 \mu \mathrm{g} / \mathrm{ml})$, the biofilm structure was destroyed. Moreover, small vesicles appeared on the surface of the cell membrane, and even the collapse and disintegration of cells were observed.

To better understand the destructive effect of Cec 4 on the biofilm, the fluorescent dyes SYTO ${ }^{\circledR} 9$ and propidium iodide were used to characterize bacteria in different states. Under the laser confocal scanning microscope, a large number of biofilm bacteria were aggregated into the control group, mainly living bacteria with green fluorescence (Figure 3). The total biomass was about $9 \times 10^{6} \mu \mathrm{m}^{3}$ and the average biofilm thickness was $>16 \mu \mathrm{m}$. The number of dead bacteria increased gradually after treated with Cec4 $(4 \mu \mathrm{g} / \mathrm{ml})$ for $2 \mathrm{~h}$. It was found that many bacteria in the visual field emitted red fluorescence. The total biomass was about $4 \times 10^{6} \mu \mathrm{m}^{3}$, and the thickness of the biofilm was reduced to $7 \mu \mathrm{m}$. Therefore, the CLSM results are consistent with the SEM observations, showing that $\mathrm{Cec} 4$ has a strong damaging effect on CRAB strain biofilm.

\section{Cec4 Decreases Twitching Motility and Surface-Associated Motility in CRAB}

Acinetobacter baumannii adheres to the surface of the object through pili, which is the initial stage of biofilm formation. Twitching motility is a unique form of movement mediated by type IV pili. A. baumannii relies on the contraction and extension of type IV pili on the surface of the Petri dish, with the inoculation point as the center, and spreads around and forms interstitial colony expansion halo. We observed that, after incubation at $37^{\circ} \mathrm{C}$ overnight, two types of the colony grew on the Petri plate. There were colonies on the surface of the agar around the inoculation point (top colony) and a visible halo of bacteria that had twitched across the plate between the bottom of the agar and the plate (interstitial colony) (Supplementary Figure S1). 

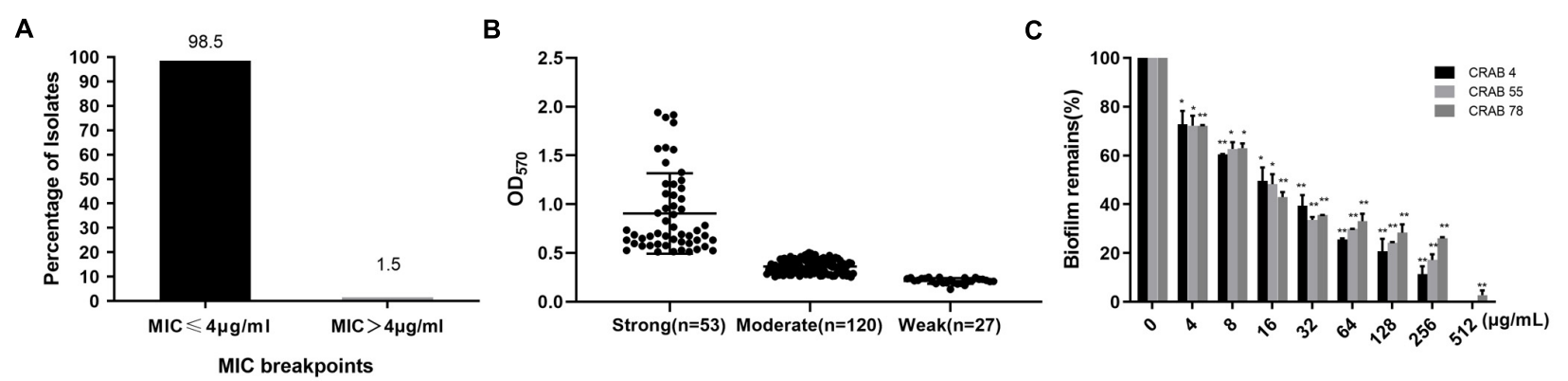

FIGURE 1 | Cec4 inhibits clinical resistant bacteria and biofilms. (A) Distribution of MIC value of Cec4 against $200 \mathrm{CRAB}$ clinical isolates ( $\mu \mathrm{g} / \mathrm{mL}$ ). (B) Quantification of biofilm formation in 200 CRAB clinical isolates. A. baumannii ATCC19606 was used as a positive control. Experiments were performed in triplicate and each bar represents the mean \pm standard deviation. (C) The effects of Cec4 on mature biofilms of CRAB. The adherent biofilm was stained by crystal violet, and then the dye was extracted with ethanol, measured at a $570-\mathrm{nm}$ absorbance, and presented as percentage of biofilm remains compared to untreated wells $(0 \mu \mathrm{g} / \mathrm{mL})$. All experiments were done in triplicate for statistical significance. ${ }^{\star} p<0.05 ;{ }^{* \star} p<0.01$.
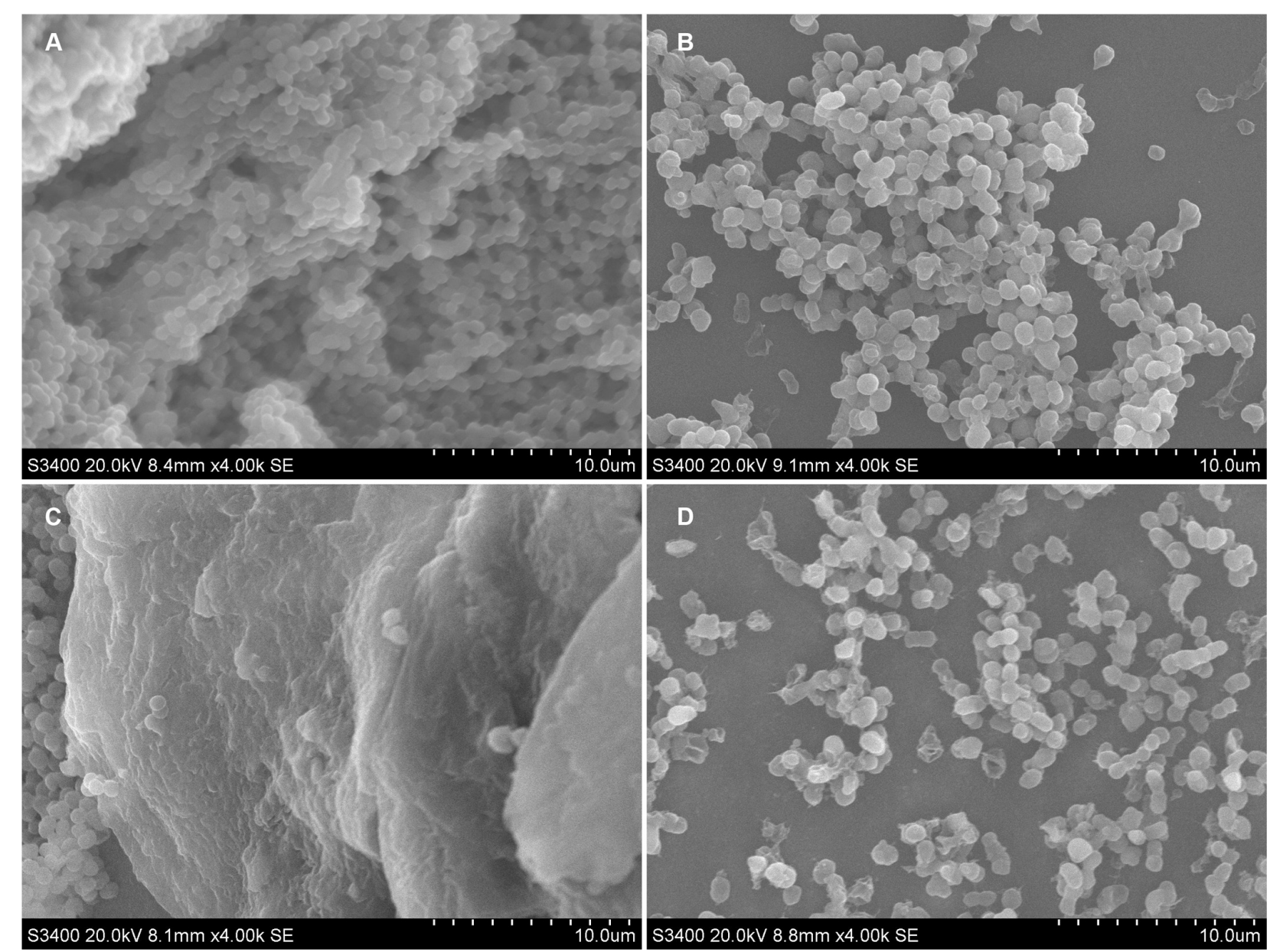

FIGURE 2 | Ultrastructural images of CRAB biofilm on sterile coverslip and catheters after treated with Cec4. (A) Coverslip without treatment, (B) Coverslip after Cec4 treatment, (C) catheter without treatment, and (D) catheter after Cec4 treatment. The selected images are the best representation of biofilms on coverslips and catheters.

Adding different concentrations of Cec4 decreased twitching motility. As the concentration of Cec4 increased, the twitching motility of bacteria decreased (Figure 4A). A. baumannii can also move on the surface of a semi-solid medium, forming round colonies at the inoculation site of the moving plate (Supplementary Figure S2). The average colony diameter of 


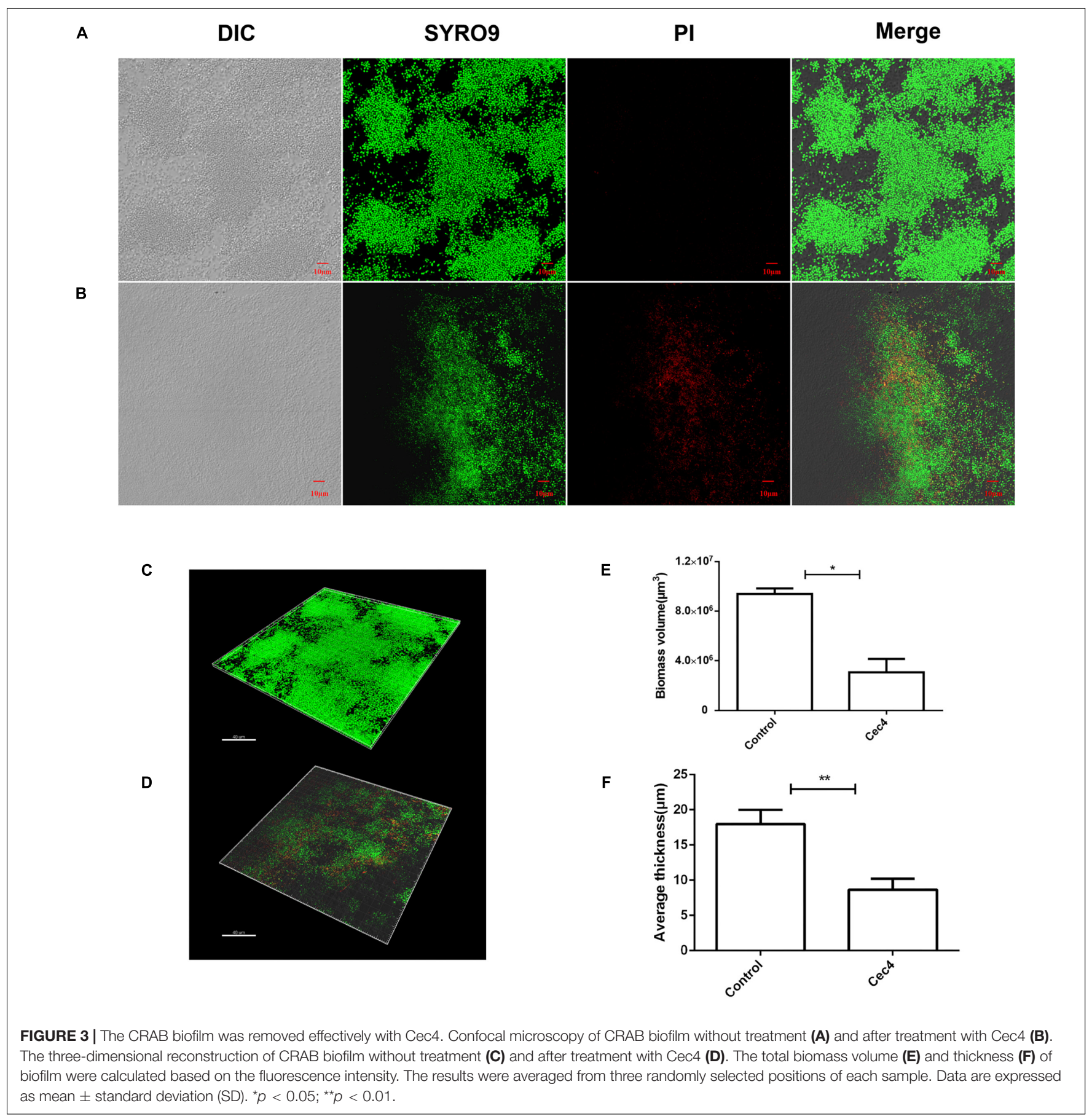

the group with Cec4 was lower than that of the control group, which was consistent with the experimental results on twitching motility (Figure 4B).

\section{Cec4 Alters the Expression of Biofilm-Related Genes}

Many studies have shown that several genes of A. baumannii are involved in the formation of biofilms and adhesion to abiotic surfaces. In order to understand the effect of
Cec4 on these genes, the RNA of biofilm bacteria under different conditions was extracted. Next, the effect of Cec4 on the expression of CsuE, BfmR, BfmS, AbaI, and Bap related to biofilm formation was evaluated using qRTPCR (Figure 4C). The results show that, compared with the control group, the pilus-related gene CsuE was downregulated 1.8-fold; the two-component regulatory system genes $B f m R$ and $B f m S$ were down-regulated 3.6-fold and 3.9-fold, respectively; the quorum-sensing regulatory gene AbaI was down-regulated 6.3-fold, and the biofilm-related 
A

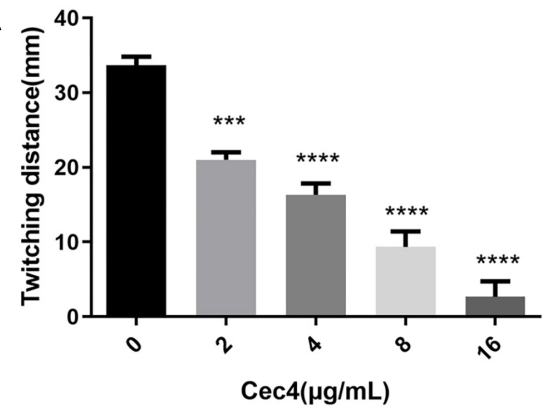

B

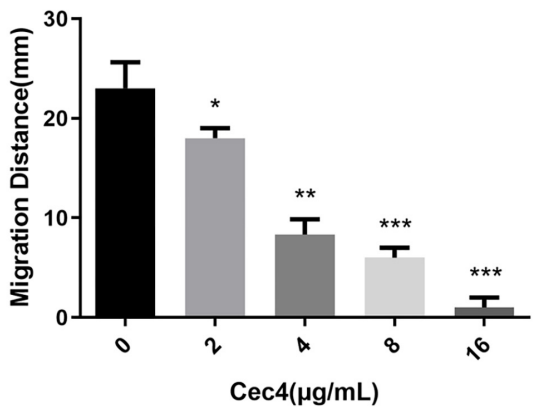

C

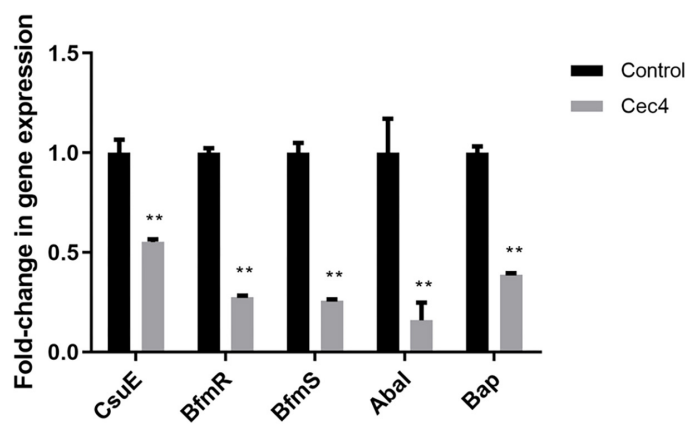

FIGURE 4 | The motility of CRAB and biofilm involved genes were affected after treated with $\mathrm{Cec} 4$. Twitching motility $(\mathbf{A})$ and surface-associated motility (B) of CRAB were quantitated from three separate experiments at $37^{\circ} \mathrm{C}$. Error bars represent standard deviation of the mean. ${ }^{*} p<0.05$; ${ }^{* *} p<0.01$; ${ }^{\star \star \star} p<0.001 ;{ }^{\star \star \star \star} p<0.0001$. (C) Effect of Cec4 on the expression levels of biofilm involved genes in CRAB strains. Error bars represent the standard deviations. ${ }^{* *} p<0.01$.

gene Bap was down-regulated 2.6-fold. These results suggest that Cec4 inhibited the expression of these genes involved in biofilm formation.

\section{Transcriptional Stress Response of CRAB Biofilm to Cec4}

The RNA sequencing results revealed the differences in gene expression between ABF and control. There were 3403 genes co-expressed in these two samples; 40 genes were specificity expressed in $\mathrm{ABF}$, and 6 genes were specificity expressed in control (Figure 5A). The volcano plots of the differentially expressed genes (DEGs) show that 185 genes were differentially expressed after Cec 4 treatment, including 132 genes that were upregulated (red) and 53 down-regulated genes (green) (Figure 5B).

\section{Analysis of Differential Gene Expression}

Transcriptome analysis revealed that the differential genes mainly included membrane protein-related genes, drug-resistant genes and pilus-related genes (Table 1). The expression of the amino acid $\mathrm{ABC}$ transporter permease, ATP-binding proteins (IX87_RS02655, IX87_RS02660, and artP) in the ABC transport system was down-regulated 1.68 -fold, 1.61 -fold, and 1.66-fold; the MFS transporter (IX87_RS20020) was down-regulated 2.96-fold, and the EamA family transporter (IX87_RS12100) expression was down-regulated 2.29-fold (Table 1). The expression of MBL fold metallo-hydrolase (IX87_RS19070) was down-regulated about 3-fold, ADC family cephalosporinhydrolyzing class C beta-lactamase (IX87_RS08365) was down-regulated 1.27-fold; adeC/adeK/oprM family multidrug efflux complex outer membrane factor (IX87_RS16845) expression was up-regulated 1.37-fold (Table 1). The protein CsuA (IX87_RS06910) was down-regulated 1.51-fold, while the expression of pili assembly chaperone (IX87_RS02530) and type 4 fimbria biogenesis proteins FimT (IX87_RS10830) was up-regulated 1.8 and 1.42-fold (Table 1).

\section{Enrichment Analysis of GO and KEGG Pathways}

To further understand the function of the DEGs underlying the effect of low concentrations of Cec4 on CRAB biofilms, GO enrichment analysis was performed with the DEGs (Figure 6A). Based on sequence homology, DEGs were assigned to one or more GO terms and categorized into three main categories of GO function (biological process, molecular function, and cellular component). It is noteworthy that in the category of biological process, protein folding, extracellular polysaccharide biosynthetic process, cellular polysaccharide metabolic process, secondary metabolite biosynthetic process, protein catabolic process, dsRNA transport and regulation of DNA-templated transcription are significantly enriched. Outer membranebounded periplasmic space and pilus are significantly enriched in the cellular component category. Enzyme activity and nucleic acid transmembrane transporter activity are enriched in the molecular function category.

By enrichment analysis, the main KEGG metabolic pathways involved in DEGs are carbon metabolism, oxidative phosphorylation, the two-component system, $\mathrm{ABC}$ transporters, nucleotide excision repair, biosynthesis of antibiotics, quorum sensing, microbial metabolism in diverse environments, and $\beta$-lactam resistance (Figure 6B). It is indicated that Cec4 affected the energy metabolism of biofilm bacteria and the bacteria two-component system. By interfering with the expression of type IV pili assembly protein in the two-component system, bacterial motility function was affected. In addition, the $\beta$-lactam antibiotics are the most widely used group of antibiotics, which exert their effect by interfering with the structural cross-linking of peptidoglycans in bacterial cell walls. Bacterial resistance to $\beta$-lactam antibiotics can be achieved by producing inactivating enzymes called $\beta$-lactamases, altering the $\beta$-lactam targets of penicillin-binding proteins (PBPs), and so on. After Cec4 treatment, genes in the $\beta$-lactam resistance pathway were 
A

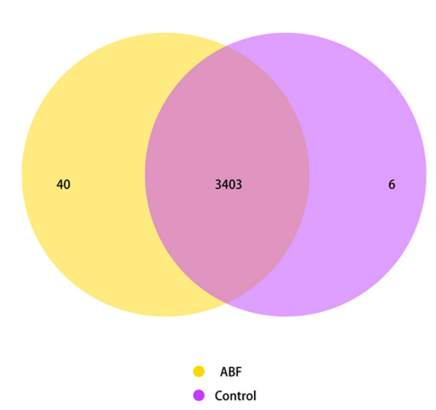

B

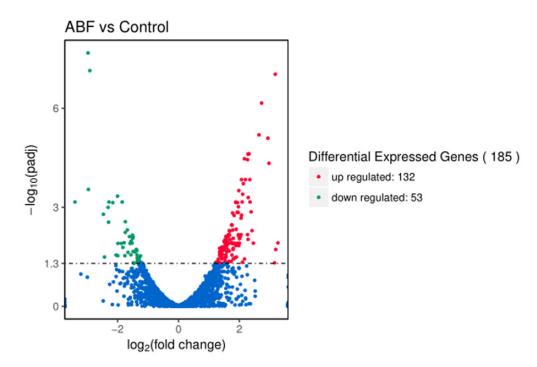

FIGURE 5 | (A) Venn diagram analysis of gene expression. The number in each circle represents the total number of genes that are expressed in each sample, and the overlapping part of circles indicates that the gene is co-expressed in both samples. (B) The volcano plots of the differentially expressed genes. Significantly differentially expressed genes were treated with red dots (up-regulated) or green dots (down-regulated). The abscissa represents fold change, and the ordinate represents statistical significance.

TABLE 1 | The genes up-regulated or down-regulated response to Cec4.

\begin{tabular}{|c|c|c|c|}
\hline Gene name & Description & $\log ^{2}$ Fold_change & Corrected $p$-value \\
\hline \multicolumn{4}{|c|}{ Membrane protein } \\
\hline IX87_RS20020 & MFS transporter & -2.96 & $2.87 \times 10^{-4}$ \\
\hline IX87_RS02655 & amino acid $A B C$ transporter permease & -1.68 & $4.86 \times 10^{-3}$ \\
\hline $\operatorname{artP}$ & amino acid ABC transporter ATP-binding protein & -1.66 & $2.30 \times 10^{-2}$ \\
\hline IX87_RS02660 & amino acid ABC transporter permease & -1.61 & $7.77 \times 10^{-3}$ \\
\hline IX87_RS12100 & EamA family transporter & -2.29 & $6.85 \times 10^{-4}$ \\
\hline \multicolumn{4}{|c|}{ Bacterial resistance } \\
\hline IX87_RS19070 & MBL fold metallo-hydrolase & -2.97 & $2.11 \times 10^{-8}$ \\
\hline IX87_RS08365 & ADC family cephalosporin-hydrolyzing class C beta-lactamase & -1.27 & $4.86 \times 10^{-2}$ \\
\hline IX87_RS16845 & adeC/adeK/oprM family multidrug efflux complex outer membrane factor & 1.37 & $2.90 \times 10^{-2}$ \\
\hline \multicolumn{4}{|l|}{ Pili } \\
\hline IX87_RS06910 & protein CsuA & -1.51 & $8.64 \times 10^{-3}$ \\
\hline IX87_RS02530 & pili assembly chaperone & 1.8 & $1.23 \times 10^{-2}$ \\
\hline IX87_RS10830 & type 4 fimbrial biogenesis protein FimT & 1.42 & $3.63 \times 10^{-2}$ \\
\hline
\end{tabular}

down-regulated. More importantly, quorum sensing (QS) allows bacteria to share information about cell density and adjust gene expression accordingly, and controls including virulence, motility, sporulation and biofilm formation. Therefore, the transcriptome results indicate that Cec4 mainly affected the expression of energy metabolism and quorum sensing signaling pathway genes.

\section{DISCUSSION}

It has been reported that after bacteria form a biofilm, the MIC value for antibiotics can be increased by 1000 times or more (Alhede et al., 2011). The antimicrobial peptide can downregulate quorum sensing, prevent the initial adhesion of bacteria to the surface, target bacteria before they form a biofilm, kill bacteria embedded in biofilms, or destroy mature biofilms to achieve the effect of inhibiting or eradicating biofilms (Batoni et al., 2016). Previous experiments have shown that Cec4 has the best antibacterial effect on A. baumannii, and it has very low hemolysis to human red blood cells even in high concentrations (600 $\mu \mathrm{g} / \mathrm{mL}$ ) (Peng et al., 2019). Our experiment results also indicated that Cec4 had little cytotoxic effect on the two human cell lines HepG2 and Hela (data not shown). In this study, 200 isolates of CRAB from different clinical patients were collected to detect their biofilm formation ability and to evaluate the inhibitory effect of $\mathrm{Cec} 4$ on biofilms. Screening at a concentration of $4 \mu \mathrm{g} / \mathrm{ml}$ revealed that $98.5 \%$ of the strains were susceptive to Cec4. Thus, Cec4 has a strong inhibitory activity against standard A. baumannii and can also inhibit clinical CRAB. The crystal violet staining method showed that the collected clinical CRAB could form biofilms, and $26.5 \%$ of the strains could strongly form a biofilm. Cec4 eradicated more than $20 \%$ of mature biofilms at a concentration of $4 \mu \mathrm{g} / \mathrm{ml}$, and the $\mathrm{MBEC}_{50}$ was $16 \mu \mathrm{g} / \mathrm{ml}$. When treated with Cec4 with a concentration of $256-512 \mu \mathrm{g} / \mathrm{ml}$, the biofilm was completely eradicated. The SEM results indicated that the biofilm formed on the medical silicone catheter was thick, with extracellular polysaccharides and other substrates that completely covered the cells. After Cec4 was treated for $2 \mathrm{~h}$, the biofilm was easily detached, and the cells were damaged or collapsed. The CLSM results further quantified the thickness and volume of the biofilms. The results show that, after $24 \mathrm{~h}$, the biofilm that formed on the coverslips was thick and dense, and mainly composed of live bacteria with a thickness 


\section{A}

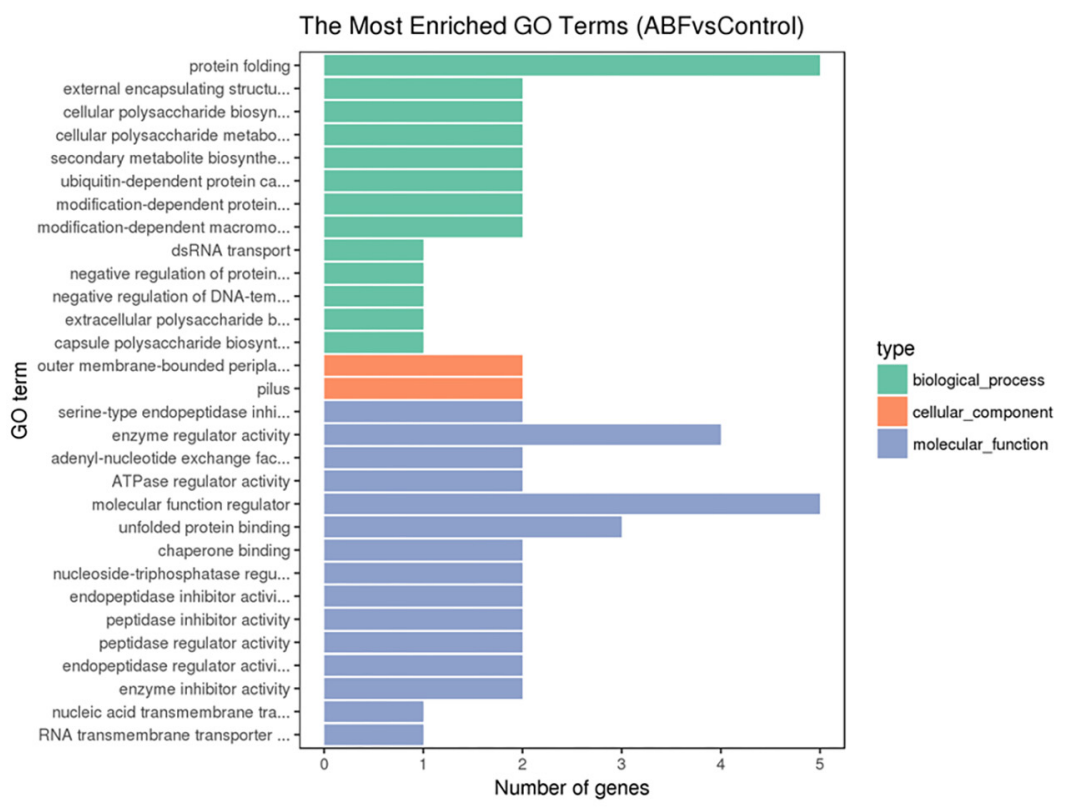

B

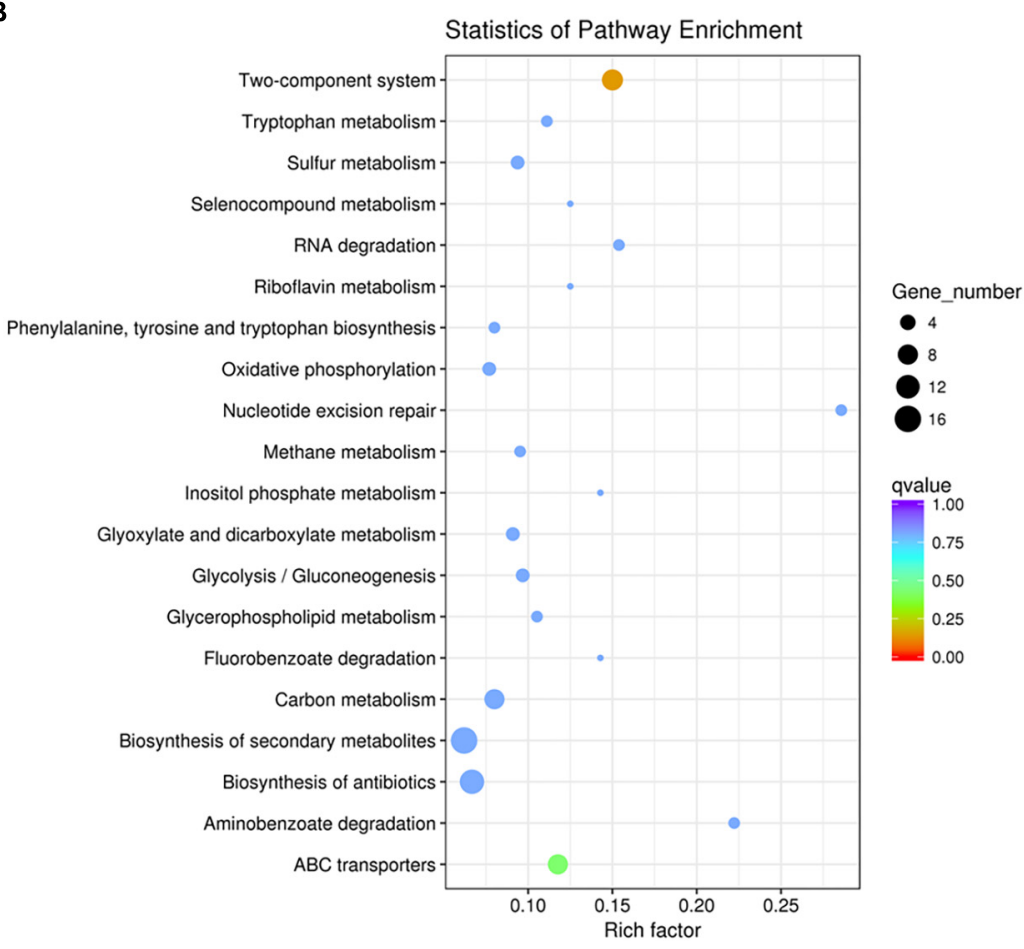

FIGURE 6 | (A) Gene Ontology (GO) analysis of differentially expressed genes. (B) Statistical enrichment of differentially expressed genes in KEGG pathways.

of 10-20 $\mu \mathrm{m}$. After treatment with Cec4, the number of dead bacteria gradually increased, and the biofilm became significantly thinner. Therefore, these results indicate that Cec 4 has a good eradication ability on biofilm forming of clinical CRAB.

It has been reported that $A$. baumannii adheres to the surface of living or non-living organisms by pili participating in the initial stage of biofilm formation, and thereby forming a biofilm. The results show that Cec4 decreased pili-mediated motility in a concentration dependent manner. Under the action of Cec4 with a sub-inhibitory concentration $(2 \mu \mathrm{g} / \mathrm{ml})$, motility was also suppressed, and no transparent halo was formed. It has been reported that peptide 1037 inhibited the swimming of $P$. aeruginosa PA14, but stimulated twitching motility (de la Fuente-Nunez et al., 2012). The expression 
of the CsuA/BABCDE chaperone complex is necessary for the assembly and production of pili associated with abiotic surface adhesion, while the Csu operon is controlled by a twocomponent system consisting of a BfmS-encoded sensor kinase and a BfmR-encoded response regulator. Insertion inactivation of $\mathrm{BfmR}$ results in the loss of expression of the CsuA/BABCDE operon, and impaired pilus production and biofilm formation (Tomaras et al., 2008). The qRT-PCR results show that Cec4 reduced the expression of $C s u E, B f m R$ and $B f m S$ genes. Clinical isolates of $A$. baumannii M2 can produce $\mathrm{N}$-acyl-homoserine lactone (3-OH-C12-HSL), a product of the abaI autoinducer synthetase gene, which is very important for the formation of complete biofilms on abiotic surfaces (Niu et al., 2008). Our research shows that $\mathrm{Cec} 4$ significantly reduced the expression of AbaI. Therefore, we speculate that Cec4 may affect quorum sensing in bacteria. In addition, A. baumannii encodes for a protein associated with the biofilm, Bap. A. baumannii strain 307-0294, mutations in large outer membrane proteins that are highly similar to Staphylococcus biofilm-associated protein (Bap) were lost, resulting in a reduction in the volume and thickness of the biofilm formed by the strain (Loehfelm et al., 2008). Cec4 reduced the expression of the Bap gene, which was consistent with its effect on the biofilm. In conclusion, Cec4 affects the expression of genes involved in the formation of $A$. baumannii biofilms, such as quorum-sensing and motility genes.

Through the neutralization or decomposition of LPS and the interference of gene expression, abnormal regulation of the genes for biofilm survival, thus inhibiting the formation of biofilm (Li et al., 2004). It has been reported that peptide 1018 can inhibit bacterial stress response via the (p)ppGpp signaling molecule (Reffuveille et al., 2014); however, there are few reports on the mechanism of inhibition and eradication of biofilm by antimicrobial peptides. To further investigate the mechanism of action of Cec4, we used RNA-Seq to study the transcriptomic profile of $\mathrm{CRAB}$ biofilms treated with Cec4. The RNA-Seq results show that gene expression of CRAB biofilms was extensively altered after Cec4 treatment. Compared with the control group, membrane proteins, bacterial resistance and pilus-related genes were differentially expressed. Iron ion as an important signal regulator mediates the expression of adhesion, and then affects the formation of biofilms (Gentile et al., 2014). Our results show that bacterial ferritin was down-regulated, iron ion uptake and storage-related gene expression were increased. Besides, drug efflux-related genes and $\mathrm{ABC}$ transporter-related genes expressions in iron-containing cells were up-regulated. GO terms were abundant in biological process categories, indicating that bacterial biological processes were significantly affected, including the synthesis and metabolism of polysaccharides and proteins. In addition, KEGG analysis showed that multiple metabolic pathways, two-component regulation systems, quorum sensing and antibiotic synthesis-related pathways in A. baumannii biofilms were affected after Cec4 treatment. Most importantly, the two-component signal transduction system regulates $\mathrm{ABC}$ transporters and type IV pili assembly proteins and participates in the growth and formation of biofilm bacteria (Xue et al., 2020). Whiteley et al. (2017) mentioned that quorum sensing is involved in the formation of biofilms. Cec4 may inhibit the growth of biofilms by affecting the quorum sensing signaling pathway. Therefore, the results show that $\mathrm{Cec} 4$ regulates the $\mathrm{CRAB}$ biofilm through multiple targets, and further experiments such as gene knockout verification are required to determine the key anti-biofilm mechanisms.

In summary, this study showed that Cec4 has good antibacterial activity against planktonic clinical CRAB and its biofilm. However, the biofilm formation of clinical strains has great differences. It is reported that resistant strains achieve high levels of biofilm-specific resistance despite producing weak biofilms (Qi et al., 2016). So, the epidemiological analysis of the 200 clinic CRAB strains is very important in understanding their genetic relationship. For example, it was shown that, of the cases of $A$. baumannii acquisition, at least $17 \%$ were cases of patientto-patient transmission in the Intensive Care Unit (Harris et al., 2019). Furthermore, deeper explorations of epidemiologic studies, such as bacterial molecular typing, drug resistance, and virulence factors detecting clinical strains, would improve our understanding of their relationship. In conclusion, these results provide a new strategy for the treatment of clinical biofilm-related infections, and also lay the foundation for the development of antimicrobial peptides as new antibacterial drugs.

\section{DATA AVAILABILITY STATEMENT}

The sequencing data in the article have been deposited at the National Center for Biotechnology Information under BioProject PRJNA607078 as SAMN14120700, SAMN14120701, SAMN14120702, SAMN14120703, SAMN14120704, SAMN1412 0705, SAMN14120706, and SAMN14120707 (https://www.ncbi. nlm.nih.gov/sra/PRJNA607078).

\section{AUTHOR CONTRIBUTIONS}

ZW and WL conceived and designed the experiments. ZW, WL, and $\mathrm{CM}$ performed the experiments. WL, ZW, ZZ, and GG analyzed the data. YF, SW, and ZZ contributed materials and analysis tools. JP and JW wrote the manuscript. All authors analyzed the data and contributed to the manuscript, gave final approval of the version to be published, and agreed to be accountable for all aspects of the work.

\section{FUNDING}

This research was funded by the National Natural Science Foundation of China (No. 81660347), the Guizhou Provincial Science and Technology Plan Project ([2017]1154), and the Key Technologies R\&D Program for Science and Technology Department of Guizhou Province ([2019]2823) is co-financed. Funders had no role in study design, data collection or analysis, preparation of the manuscript or the decision to publish 
it. We also thank proof-reading-service for proofreading the manuscript (www.proof-reading-service.com).

\section{SUPPLEMENTARY MATERIAL}

The Supplementary Material for this article can be found online at: https://www.frontiersin.org/articles/10.3389/fmicb. 2020.01532/full\#supplementary-material

\section{REFERENCES}

Abouelhassan, Y., Yang, Q., Yousaf, H., Nguyen, M. T., Rolfe, M., Schultz, G. S., et al. (2017). Nitroxoline: a broad-spectrum biofilm-eradicating agent against pathogenic bacteria. Int. J. Antimicrob. Agents 49, 247-251. doi: 10.1016/j. ijantimicag.2016.10.017

Aisenbrey, C., Marquette, A., and Bechinger, B. (2019). The mechanisms of action of cationic antimicrobial peptides refined by novel concepts from biophysical investigations. Adv. Exp. Med. Biol. 1117, 33-64. doi: 10.1007/978-981-133588-4_4

Akalay, S., Vanassche, T., and De Munter, P. (2020). Tigecycline-induced lifethreatening coagulopathy in a patient with a Mycobacterium abscess: a case report and step-by-step diagnostic approach. Acta Clin. Belg. 1-5. doi: 10.1080/ 17843286.2020.1747197 [Epub ahead of print].

Alhede, M., Kragh, K. N., Qvortrup, K., Allesen-Holm, M., Van Gennip, M., Christensen, L. D., et al. (2011). Phenotypes of non-attached Pseudomonas aeruginosa aggregates resemble surface attached biofilm. PLoS One 6:e27943. doi: 10.1371/journal.pone.0027943

Alvarez-Fraga, L., Perez, A., Rumbo-Feal, S., Merino, M., Vallejo, J. A., Ohneck, E. J., et al. (2016). Analysis of the role of the LH92_11085 gene of a biofilm hyper-producing Acinetobacter baumannii strain on biofilm formation and attachment to eukaryotic cells. Virulence 7, 443-455. doi: 10.1080/21505594. 2016.1145335

Anders, S., and Huber, W. (2012). Differential Expression of RNA-Seq Data at the Gene Level-the DESeq Package. Heidelberg: EMBL.

Badmasti, F., Siadat, S. D., Bouzari, S., Ajdary, S., and Shahcheraghi, F. (2015). Molecular detection of genes related to biofilm formation in multidrug-resistant Acinetobacter baumannii isolated from clinical settings. J. Med. Microbiol. 64, 559-564. doi: 10.1099/jmm.0.000058

Batoni, G., Maisetta, G., Brancatisano, F. L., Esin, S., and Campa, M. (2011). Use of antimicrobial peptides against microbial biofilms: advantages and limits. Curr. Med. Chem. 18, 256-279. doi: 10.2174/092986711794088399

Batoni, G., Maisetta, G., and Esin, S. (2016). Antimicrobial peptides and their interaction with biofilms of medically relevant bacteria. Biochim. Biophys. Acta 1858, 1044-1060. doi: 10.1016/j.bbamem.2015.10.013

Bentancor, L. V., Camacho-Peiro, A., Bozkurt-Guzel, C., Pier, G. B., and Maira-Litran, T. (2012). Identification of Ata, a multifunctional trimeric autotransporter of Acinetobacter baumannii. J. Bacteriol. 194, 3950-3960. doi: 10.1128/JB.06769-11

Boca, S. M., and Leek, J. T. (2018). A direct approach to estimating false discovery rates conditional on covariates. PeerJ. 6:e6035. doi: 10.7717/peerj.6035

Bortolin, M., De Vecchi, E., Romano, C. L., Toscano, M., Mattina, R., and Drago, L. (2016). Antibiofilm agents against MDR bacterial strains: is bioactive glass BAG-S53P4 also effective? J. Antimicrob. Chemother. 71, 123-127. doi: 10.1093/ $\mathrm{jac} / \mathrm{dkv} 327$

Cai, Y., and Wang, R. (2011). Tigecycline: benefits and risks. Lancet Infect. Dis. 11, 804-805. doi: 10.1016/s1473-3099(11)70183-9

Dafopoulou, K., Vourli, S., Tsakris, A., and Pournaras, S. (2019). An update on polymyxin susceptibility testing methods for Acinetobacter baumannii. Expert Rev. Anti Infect. Ther. 17, 699-713. doi: 10.1080/14787210.2019.16 67230

de la Fuente-Nunez, C., Korolik, V., Bains, M., Nguyen, U., Breidenstein, E. B., Horsman, S., et al. (2012). Inhibition of bacterial biofilm formation and swarming motility by a small synthetic cationic peptide. Antimicrob. Agents Chemother. 56, 2696-2704. doi: 10.1128/AAC.00064-12
FIGURE S1 | Images of twitching motility after treated with Cec4. From left to right (A-E), the concentration of Cec4 is $0,2,4,8,16 \mu \mathrm{g} / \mathrm{ml}$.

FIGURE S2 | Images of surface-associated motility after treated with Cec4. From left to right (A-E), the concentration of Cec4 is $0,2,4,8,16 \mu \mathrm{g} / \mathrm{ml}$.

TABLE S1 | Oligonucleotide primers used in this study.

TABLE S2 | The MICs, MBIC, MBEC, sample source and drug susceptibility of 200 CRAB strains.

de la Fuente-Nunez, C., Reffuveille, F., Haney, E. F., Straus, S. K., and Hancock, R. E. (2014). Broad-spectrum anti-biofilm peptide that targets a cellular stress response. PLoS Pathog. 10:e1004152. doi: 10.1371/journal.ppat.1004152

Eze, E. C., Chenia, H. Y., and El Zowalaty, M. E. (2018). Acinetobacter baumannii biofilms: effects of physicochemical factors, virulence, antibiotic resistance determinants, gene regulation, and future antimicrobial treatments. Infect. Drug Resist. 11, 2277-2299. doi: 10.2147/idr.s169894

Feng, X., Sambanthamoorthy, K., Palys, T., and Paranavitana, C. (2013). The human antimicrobial peptide LL-37 and its fragments possess both antimicrobial and antibiofilm activities against multidrug-resistant Acinetobacter baumannii. Peptides 49, 131-137. doi: 10.1016/j.peptides.2013. 09.007

Gentile, V., Frangipani, E., Bonchi, C., Minandri, F., Runci, F., and Visca, P. (2014). Iron and Acinetobacter baumannii biofilm formation. Pathogens 3, 704-719. doi: $10.3390 /$ pathogens 3030704

Giammanco, A., Cala, C., Fasciana, T., and Dowzicky, M. J. (2017). Global assessment of the activity of tigecycline against multidrug-resistant gramnegative pathogens between 2004 and 2014 as part of the tigecycline evaluation and surveillance trial. $m$ Sphere 2:e0310-16. doi: 10.1128/mSphere. 00310-16

Handal, R., Handal, R., Qunibi, L., Sahouri, I., Juhari, M., Dawodi, R., et al. (2017). Characterization of carbapenem-resistant Acinetobacter baumannii strains isolated from hospitalized patients in palestine. Int. J. Microbiol. 2017:8012104. doi: 10.1155/2017/8012104

Harding, C. M., Tracy, E. N., Carruthers, M. D., Rather, P. N., Actis, L. A., and Munson, R. S. Jr. (2013). Acinetobacter baumannii strain M2 produces type IV pili which play a role in natural transformation and twitching motility but not surface-associated motility. mBio 4:e00360-13. doi: 10.1128/mBio.00360- 13

Harris, A. D., Johnson, J. K., Pineles, L., O’Hara, L. M., Bonomo, R. A., and Thom, K. A. (2019). Patient-to-patient transmission of Acinetobacter baumannii gastrointestinal colonization in the intensive care unit. Antimicrob. Agents Chemother. 63:e00392-19.

He, X., Lu, F., Yuan, F., Jiang, D., Zhao, P., Zhu, J., et al. (2015). Biofilm formation caused by clinical Acinetobacter baumannii isolates is associated with overexpression of the AdeFGH efflux pump. Antimicrob. Agents Chemother. 59, 4817-4825. doi: 10.1128/AAC.00877-15

Humphries, R. M., Ambler, J., Mitchell, S. L., Castanheira, M., Dingle, T., Hindler, J. A., et al. (2018). CLSI methods development and standardization working group best practices for evaluation of antimicrobial susceptibility tests. J. Clin. Microbiol. 56:e01934-17. doi: 10.1128/JCM.01934-17

Jamal, M., Ahmad, W., Andleeb, S., Jalil, F., Imran, M., Nawaz, M. A., et al. (2018). Bacterial biofilm and associated infections. J. Chin. Med. Assoc. 81, 7-11. doi: 10.1016/j.jcma.2017.07.012

Kanehisa, M., Araki, M., Goto, S., Hattori, M., Hirakawa, M., Itoh, M., et al. (2008). KEGG for linking genomes to life and the environment. Nucl. Acids Res. 36, D480-D484. doi: 10.1093/nar/gkm882

Kim, S., Lee, D.-W., Jin, J.-S., and Kim, J. (2020). Antimicrobial activity of LysSS, a novel phage endolysin, against Acinetobacter baumannii and Pseudomonas aeruginosa. J. Glob. Antimicrob. Resist. 22, 32-39. doi: 10.1016/j.jgar.2020.01. 005

Langmead, B., and Salzberg, S. L. (2012). Fast gapped-read alignment with Bowtie 2. Nat. Methods 9, 357-359. doi: 10.1038/nmeth.1923

Li, P., Wohland, T., Ho, B., and Ding, J. L. (2004). Perturbation of Lipopolysaccharide (LPS) Micelles by Sushi 3 (S3) antimicrobial peptide. The importance of an intermolecular disulfide bond in $S 3$ dimer for binding, 
disruption, and neutralization of LPS. J. Biol. Chem. 279, 50150-50156. doi: 10.1074/jbc.M405606200

Lin, M. F., Lin, Y. Y., and Lan, C. Y. (2019). A method to assess influence of different medical tubing on biofilm formation by Acinetobacter baumannii. J. Microbiol. Methods 160, 84-86. doi: 10.1016/j.mimet.2019.03.023

Loehfelm, T. W., Luke, N. R., and Campagnari, A. A. (2008). Identification and characterization of an Acinetobacter baumannii biofilm-associated protein. J. Bacteriol. 190, 1036-1044. doi: 10.1128/JB.01416-07

Long, H., Yang, J., Peng, J., and Wu, J. W. (2017). Antimicrobial activity of Musca domestica cecropin - 4 (mdCec 4$)$ against Acinetobacter baumannii. Chin. J. Microbiol. Immunol. 37, 891-896. doi: 10.3760/cma.j.issn.0254-5101.2017.12. 002

Maragakis, L. L., and Perl, T. M. (2008). Acinetobacter baumannii: epidemiology, antimicrobial resistance, and treatment options. Clin. Infect. Dis. 46, 1254-1263. doi: $10.1086 / 529198$

McQueary, C. N., and Actis, L. A. (2011). Acinetobacter baumannii biofilms: variations among strains and correlations with other cell properties. J. Microbiol. 49, 243-250. doi: 10.1007/s12275-011-0343-7

Neshani, A., Sedighian, H., Mirhosseini, S. A., Ghazvini, K., Zare, H., and Jahangiri, A. (2020). Antimicrobial peptides as a promising treatment option against Acinetobacter baumannii infections. Microb. Pathog. 146:104238. doi: 10.1016/ j.micpath.2020.104238

Niu, C., Clemmer, K. M., Bonomo, R. A., and Rather, P. N. (2008). Isolation and characterization of an autoinducer synthase from Acinetobacter baumannii. J. Bacteriol. 190, 3386-3392. doi: 10.1128/JB.01929-07

O'Shea, M. K. (2012). Acinetobacter in modern warfare. Int. J. Antimicrob. Agents 39, 363-375. doi: 10.1016/j.ijantimicag.2012.01.018

O’Toole, G. A. (2011). Microtiter dish biofilm formation assay. J. Vis. Exp. 2437. doi: $10.3791 / 2437$

Peng, J., Long, H., Liu, W., Wu, Z., Wang, T., Zeng, Z., et al. (2019). Antibacterial mechanism of peptide Cec4 against Acinetobacter baumannii. Infect. Drug Resist. 12, 2417-2428. doi: 10.2147/idr.s214057

Qi, L., Li, H., Zhang, C., Liang, B., Li, J., Wang, L., et al. (2016). Relationship between antibiotic resistance, biofilm formation, and biofilm-specific resistance in Acinetobacter baumannii. Front. Microbiol. 7:483. doi: 10.3389/fmicb.2016. 00483

Qin, N., Tan, X., Jiao, Y., Liu, L., Zhao, W., Yang, S., et al. (2014). RNA-Seqbased transcriptome analysis of methicillin-resistant Staphylococcus aureus biofilm inhibition by ursolic acid and resveratrol. Sci. Rep. 4:5467. doi: 10.1038/ srep05467

Ramalingam, K., and Lee, V. A. (2018). Antibiofilm activity of an EDTA-containing nanoemulsion on multidrug-resistant Acinetobacter baumannii. Artif. Cells Nanomed. Biotechnol. 46, 737-743. doi: 10.1080/21691401.2018.1468771

Reffuveille, F., De La Fuente-Nunez, C., Mansour, S., and Hancock, R. E. (2014). A broad-spectrum antibiofilm peptide enhances antibiotic action against bacterial biofilms. Antimicrob. Agents Chemother. 58, 5363-5371. doi: 10.1128/AAC. 03163-14

Rivals, I., Personnaz, L., Taing, L., and Potier, M. C. (2007). Enrichment or depletion of a go category within a class of genes: which test? Bioinformatics 23, 401-407. doi: 10.1093/bioinformatics/btl633

Saugar, J. M., Alarcon, T., Lopez-Hernandez, S., Lopez-Brea, M., Andreu, D., and Rivas, L. (2002). Activities of Polymyxin B and Cecropin A-Melittin Peptide
CA(1-8)M(1-18) against a multiresistant strain of Acinetobacter baumannii. Antimicrob. Agents Chemother. 46, 875-878. doi: 10.1128/aac.46.3.875878.2002

Singh, N., Rajwade, J., and Paknikar, K. M. (2019). Transcriptome analysis of silver nanoparticles treated Staphylococcus aureus reveals potential targets for biofilm inhibition. Colloids Surf. B Biointerf. 175, 487-497. doi: 10.1016/j.colsurfb.2018. 12.032

Spapen, H., Jacobs, R., Van Gorp, V., Troubleyn, J., and Honore, P. M. (2011). Renal and neurological side effects of colistin in critically ill patients. Ann. Intensive Care 1:14. doi: 10.1186/2110-5820-1-14

Tomaras, A. P., Flagler, M. J., Dorsey, C. W., Gaddy, J. A., and Actis, L. A. (2008). Characterization of a two-component regulatory system from Acinetobacter baumannii that controls biofilm formation and cellular morphology. Microbiology 154, 3398-3409. doi: 10.1099/mic.0.2008/01 9471-0

Trapnell, C., Roberts, A., Goff, L., Pertea, G., Kim, D., Kelley, D. R., et al. (2012). Differential gene and transcript expression analysis of RNA-seq experiments with TopHat and Cufflinks. Nat. Protoc. 7, 562-578. doi: 10.1038/nprot.2012. 016

Whiteley, M., Diggle, S. P., and Greenberg, E. P. (2017). Bacterial quorum sensing: the progress and promise of an emerging research area. Nature 551, 313-320. doi: $10.1038 /$ nature 24624

Wiegand, I., Hilpert, K., and Hancock, R. E. W. (2008). Agar and broth dilution methods to determine the minimal inhibitory concentration (MIC) of antimicrobial substances. Nature Protoc. 3, 163-175. doi: 10.1038/nprot.2007. 521

Williams, D. L., and Costerton, J. W. (2012). Using biofilms as initial inocula in animal models of biofilm-related infections. J. Biomed. Mater. Res. B Appl. Biomater. 100, 1163-1169. doi: 10.1002/jbm.b.31979

Wu, S., Liu, Y., Zhang, H., and Lei, L. (2019). The pathogenicity and transcriptome analysis of methicillin-resistant Staphylococcus aureus in response to water extract of Galla chinensis. Evid. Based Complement. Alternat. Med. 2019:3276156. doi: 10.1155/2019/3276156

Xue, M., Raheem, M. A., Gu, Y., Lu, H., Song, X., Tu, J., et al. (2020). The $\mathrm{KdpD} / \mathrm{KdpE}$ two-component system contributes to the motility and virulence of avian pathogenic Escherichia coli. Res. Vet. Sci. 131, 24-30. doi: 10.1016/j. rvsc.2020.03.024

Young, M. D., Wakefield, M. J., Smyth, G. K., and Oshlack, A. (2010). Gene ontology analysis for RNA-seq: accounting for selection bias. Genome Biol. 11:R14. doi: 10.1186/gb-2010-11-2-r14

Conflict of Interest: The authors declare that the research was conducted in the absence of any commercial or financial relationships that could be construed as a potential conflict of interest.

Copyright (c) $2020 \mathrm{Liu}, \mathrm{Wu}$, Mao, Guo, Zeng, Fei, Wan, Peng and Wu. This is an open-access article distributed under the terms of the Creative Commons Attribution License (CC BY). The use, distribution or reproduction in other forums is permitted, provided the original author(s) and the copyright owner(s) are credited and that the original publication in this journal is cited, in accordance with accepted academic practice. No use, distribution or reproduction is permitted which does not comply with these terms. 